\title{
Chemical modifications and transformations of 3-azahetarylchroman-4-ones
}

\author{
Natalia V. Gorbulenko*, Tatyana V. Shokol, \\ Vladimir P. Khilya \\ Department of Chemistry, Taras Shevchenko National University of Kyiv, \\ Lva Tolstogo Street 12, 01601 Kyiv, Ukraine \\ ngorbulenko@ukr.net
}

Keywords: chromones, hydrogenated chromone derivatives, 3-azahetarylchromones, 3azahetarylchroman-4-ones, chromanone oxime, chromanone oxime ether, chromanone hydrazone, pyrazoline, conformationally constrained analogs of drugs, antifungal activity, antibacterial activity, anticonvulsant activity

Articles reporting on the chemical modifications and transformations of 3-azahetarylchroman-4ones are reviewed. The following transformations of 3-azahetarylchroman-4-ones including reduction into corresponding 3-azahetarylchromanols, -chromenes or -3,4-dihydrochromenes, alkylation of 3-azahetarylchromanols, reconversion of 3-azahetarylchroman-4-ones into 3azahetarylchromones, formation of 3-hetarylchroman-4-one oximes and corresponding oxime ethers, recyclization into 3-aryl-4-hetarylpyrazolines are discussed. The biological activity data for 3-azahetarylchroman-4-one derivatives and products of their transformations is also adduced.

\section{Introduction}

The hydrogenated chromone derivatives are of indubitable interest, owing to a wide spectrum of their biological activity (estrogenic, anticancer antiinflammatory, antioxidative, hepato-protective, antimicrobial, hypolipidemic et al.) $[1,2]$. Being in the same molecule $\mathrm{N}$ containing heterocycles and chromone or chroman rings represent a useful source of exploratory chemistry for discovery of novel biologically active compounds (Figure 1).<smiles>O=C1CCOc2ccccc2C1=O</smiles>

Figure 1. General formulas of chromone derivatives row Carrying out systematic investigation of chemical and biological properties of 3- 
azahetarylchromones we took into consideration the synthesis, chemical modification and transformation of hydrogenated 3azahetarylchromones. The small difference in the structure of 3-azahetarylchroman-4-ones and 3-azahetarylchromones resulted in big difference in their chemistry and bioactivity.

\section{Results and discussion}

In the progress to determine the chemical potential of 3-azahetarylchroman-4ones and in the search for new compounds of pharmacological interest the following modifications and transformations of 3azahetarylchroman-4-ones were carried out. There are different derivatives obtained by hydrogenation of 3-azahetarylchromon-4-ones, 3-azahetarylchromon-4-ones conversion products in reactions with nucleophiles (C-4 modified 3-azahetarylchromon-4-ones, such as oximes and hydrazones derivatives or the cleavage products of the benzopyrane ring of 3azahetarylchromon-4-ones, such as isoxazoline and pyrazoline derivatives), the products of electrophilic attack by formaldehyde and reconversion products into 3azahetarylchromones.

\section{Synthesis of 3-azahetarylchroman-4-ols, - chromenes and -3,4-dihydrochromenes}

The up-to-date state of researches on 3azahetarylchroman-4-ones' synthesis and biological activity was early reflected in mini review [3]. The present article complements previous review and is dedicated to the chemical properties of 3-azahetarylchroman-4-ones and the biological activities of 3-azahetarylchroman4-one modification or transformation products.

3-Hetarylchroman-4-ones may be used as starting materials to obtain the corresponding 3hetarylchromanols, -chromenes and -3,4dihydrochromenes. The hydrogenated derivatives of 3-azahetarylchroman-4-ones were synthesized following classical reduction procedures.

Thus catalytic hydrogenation of 3-piperidinochroman-4-one hydrochloride (1) in $0,1 \mathrm{~N} \mathrm{HCl}$ with $10 \% \mathrm{Pd}$ on carbon powder was used to obtain 3-piperidinochroman-4-ol

(Scheme 1).

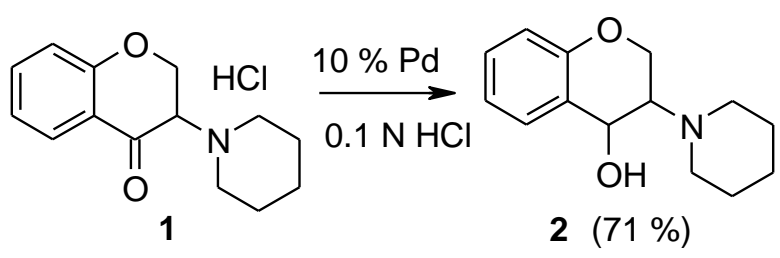

Scheme 1. The synthesis of 3-piperidinochroman-4-ol Stereochemistry?

In the case of 3-(imidazol-1-yl)-6-R-chroman-4ones (3) the reduction with $\mathrm{NaBH}_{4}$ gave a mixture of cis- and trans-3-(imidazol-1-yl)-6-Rchroman-4-ols (4), which was separated on a silica gel chromatographic column for chlorine derivative. The above mixtures of chromanols 4 by alkylation with alkyl or benzyl halides gave 
the ethers (5, cis-trans mixture) and by show interesting activities both in vitro and in dehydration in acidic medium yielded 3- vivo [5]. Thus chroman-4-one $3(\mathrm{R}=6-\mathrm{Cl})$ and (imidazol-1-yl)-6-R-2H-chromenes

(6), the corresponding chroman-4-ol 4 showed subsequent hydrogenation of later ones resulted significant hypolipidemic activity in in formation of 3-(imidazol-1-yl)-6-R-3,4- normolipemic rats. Both substances dihydro-2H-chromene 7 (Scheme 2).

These compounds were undergoing cholesterol, the hypocholesterolemic effect pharmacological evaluation as hypolipaemic being particularly strong on LDL so that the and antiatherosclerotic agents. Some of them HDL/LDL ratio was markedly raised [6].

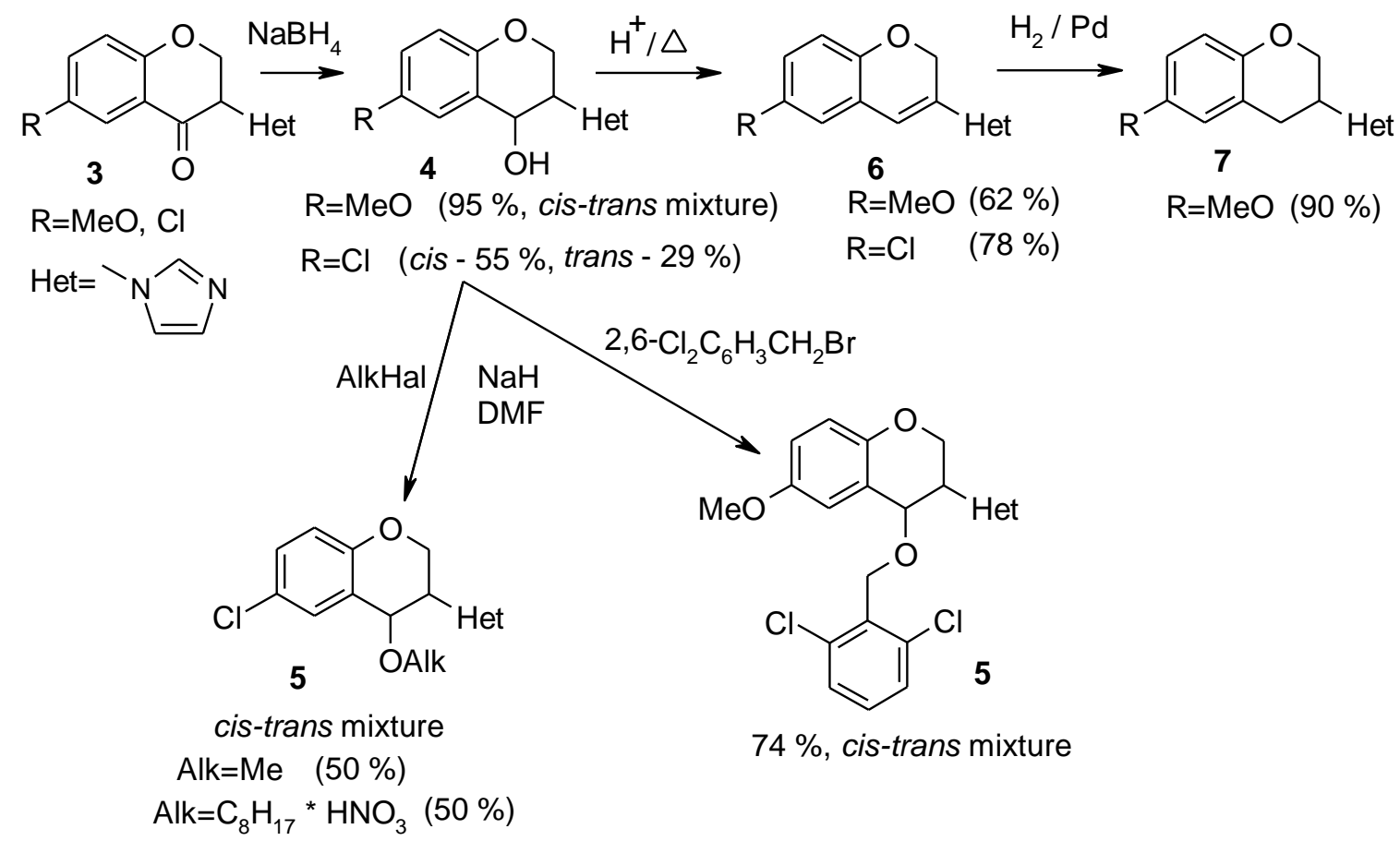

Scheme 2. The synthesis of 3-(imidazol-1-yl)chroman-4-ols, corresponding ethers, chromenes and 3,4dihydrochromenes $-\mathrm{Hal}$ is not defined, what is $\mathrm{C}_{8} \mathrm{H}_{17} * \mathrm{HNO}_{3}$ ?

Alkyl and benzyl ethers 5 can be considered as cyclic analogues of antifungal agents such as miconazole and isosters of the 2-(1H-imidazol1-yl)-1-benzyloxytetralines (Scheme 2). The latest were active in vitro against Gram-positive bacteria, Candida albicans and dermatophytes [5].

It was found chromanols $\mathbf{4}$ retain the hypolipemic activity of the corresponding chroman-4-ones $\mathbf{3}$, but when the alcoholic group is alkylated (5), or when the oxygenated function adjacent to the imidazolyl residue is removed (6), the activity disappears [6].

\section{3-(1-Imidazolyl)-2,3-dihydro-4H-1-benzo-} pyran derivatives of the following general formula 8, have been patented (Figure 2), as well as method of preparation, pharmaceutical compositions and method of using such 
compounds to inhibit blood platelet aggregation, to increase total serum HDL cholesterol, to increase the ratio between $\alpha$-lipoprotein and $\beta$ lipoprotein total cholesterol, and/or reducing total serum cholesterol or serum triglycerides [7].

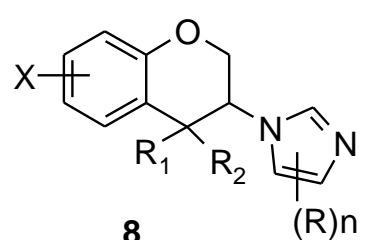

$$
\begin{aligned}
& \mathrm{R}=\mathrm{C}_{1}-\mathrm{C}_{6} \text { alkyl } \\
& \mathrm{n}=0-3
\end{aligned}
$$

one of the $\mathrm{R}_{1}$ and $\mathrm{R}_{2}$ is $\mathrm{OH}$,

and the other is $\mathrm{H}$ or $\mathrm{C}_{1}-\mathrm{C}_{6}$ alkyl

or $\mathrm{R}_{1}+\mathrm{R}_{2}$ form an oxo group

$\mathrm{X}=\mathrm{H}, \mathrm{C}_{1}-\mathrm{C}_{6}$ alkyl, $\mathrm{Ph}$, phenylthio, Hal,

$\mathrm{OH}$, phenoxy, (un)substituted benzyl etc.

Figure 2. General formula of patented 3-(1-imidazolyl)2,3-dihydro-4H-1-benzopyran derivatives

The reduction of 3-(1-imidazolyl)chroman-4one derivatives may be performed by treatment with $\mathrm{NaBH}_{4}$ in methyl or ethyl alcohol, or $\mathrm{LiAlH}_{4}$ in anhydrous THF, diethyl ether at temperature ranging from about $0^{\circ} \mathrm{C}$ to reflux temperature. It can also be used catalytic hydrogenation in the presence of palladium, platinum, platinum oxide, ruthenium or Raneynickel in methyl or ethyl alcohol, acetic acid, $n$ hexane etc., operating at a pressure ranging from atmospheric pressure to about 50 atmospheres and at temperature ranging from about $20^{\circ}$ to about $100^{\circ} \mathrm{C}$ [7](Appropriate refs have to be added). The synthesis of 3-(1imidazolyl)-4-alkylchroman-4-ol $8 \quad\left(\mathrm{R}^{1}=\mathrm{OH}\right.$, $\mathrm{R}^{2}=\mathrm{Alkyl}$ ) derivatives was carried out by reaction of 3-(1-imidazolyl)chroman-4-one derivatives with a compound $\mathrm{RZ}(\mathrm{Z}$ is $\mathrm{Li}$ or the group $\mathrm{MgHal}$ and $\mathrm{R}$ is $\mathrm{C}_{1}-\mathrm{C}_{6}$ alkyl) in anhydrous $n$-hexane at temperature ranging from about $60^{\circ} \mathrm{C}$ to about $-80^{\circ} \mathrm{C}$ (for RLi) or in anhydrous diethyl ether at temperature ranging from about $0^{\circ} \mathrm{C}$ to room temperature (RMgHal) [7]. Ref?

3-(1-Imidazolyl)-2H-chromene and -3,4dihydro- $2 H$-chromene derivatives of the following general formula 9 (Figure 3) have been patented and shown in some cases to be better inhibitory of platelet aggregation than, e.g. 6-chloro-2,3-dihydro-3-(1-imidazolyl)-4Hbenzopyran-4-one (3) [8].

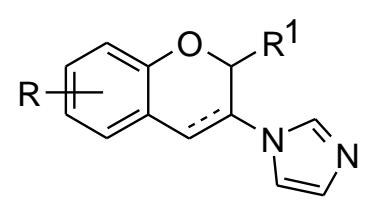

9

$\mathrm{R}_{1}=\mathrm{H}, \mathrm{C}_{1}-\mathrm{C}_{6}$ alkyl or cycloalkyl, $\mathrm{Ar}$, 3-Py

$\mathrm{R}=\mathrm{H}, \mathrm{Cl}, \mathrm{MeO}, \mathrm{COOH}, \mathrm{COOi}-\mathrm{Pr}, \mathrm{COO}$-vinyl, COOEt, $\mathrm{OH}, \mathrm{OC}(\mathrm{Me})_{2} \mathrm{COOH}$

Figure 3. 3-(1-Imidazolyl)-2H-chromene and -3,4dihydro- $2 H$-chromene derivatives inhibiting platelet aggregation

Hypolipidaemic and antiatherosclerotic imidazol-2-yl-derivatives of bicyclic compounds $\mathbf{1 0}$ and process for their preparation (Scheme 3) have also been patented [9]. Compounds having formula $\mathbf{1 0}$ and the pharmaceutically acceptable salts thereof have been proposed for use in therapy in particular for the prevention of the coronary heart disease. 
<smiles>[R]C1Oc2cc(O)ccc2C(=O)C1[Hg]Cl</smiles>

$\mathrm{NaBH}_{4}$<smiles>CCO[C@H](CO)[C@H](OC)OCC</smiles><smiles>[R2]C1Oc2ccc(O)cc2C(O)C1C</smiles>

$\mathrm{AcOH}$ or

$\mathrm{Ac}_{2} \mathrm{O} / \mathrm{Pd}$

kat. $\mathrm{H}_{2} \mathrm{SO}_{4}, \mathrm{HCl}$
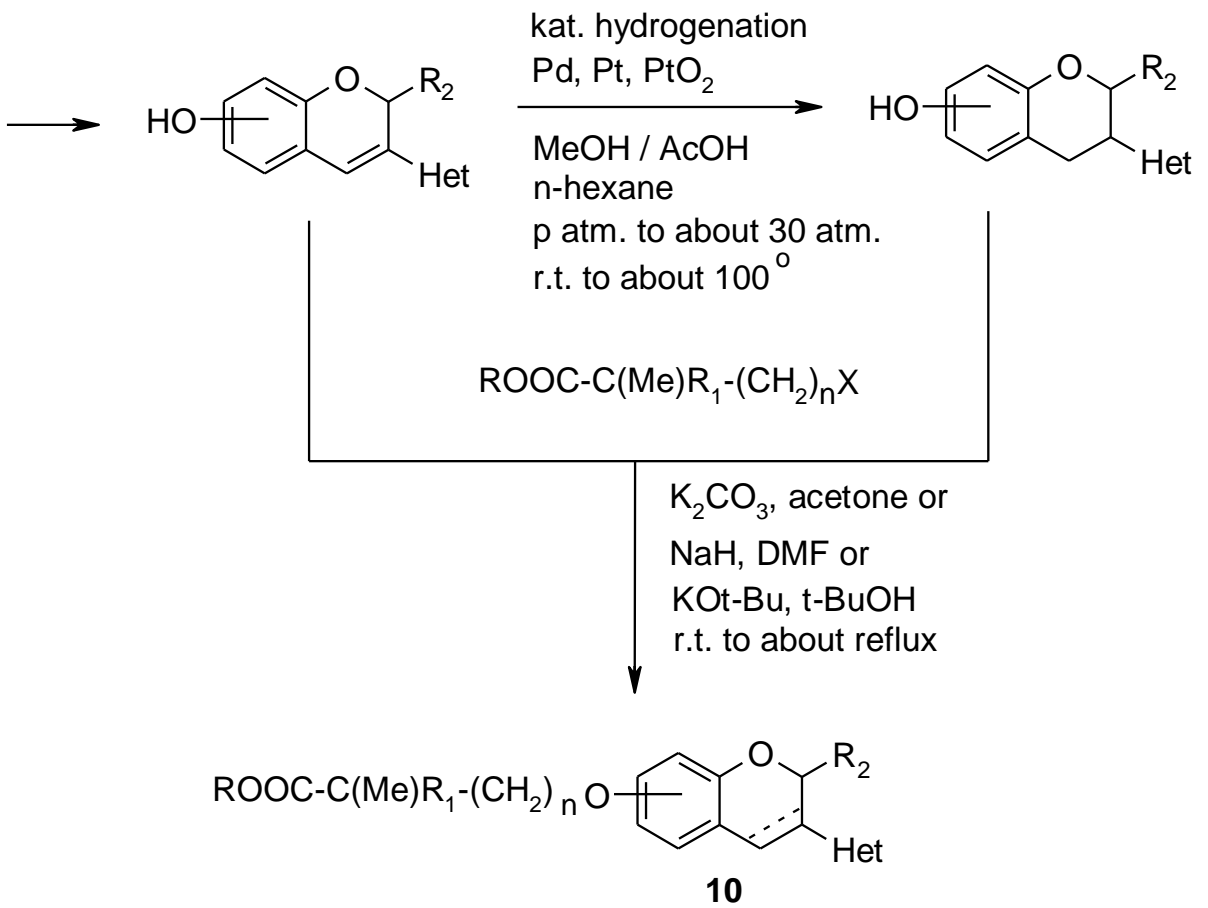

$X=\mathrm{Hal}$, active ester mesyl or tosyl

$n=0-3$

$R, R_{1}=H, C_{1}-C_{4}$-alkyl

$\mathrm{R}_{2}, \mathrm{R}_{3}=\mathrm{H}, \mathrm{C}_{1}-\mathrm{C}_{8}$-alkyl<smiles>Cc1nccn1P</smiles>

Scheme 3. Hypolipidaemic and antiatherosclerotic 3-(imidazol-2-yl)- $2 \mathrm{H}$-chromenes and -3,4-dihydro- $2 \mathrm{H}$-chromenes

2,6-Disubstituted 3-(imidazol-2-yl)benzopyrans

10 with significant in vitro acyl CoA cholesterol acyltransferase (ACAT) inhibitory activity were reported (Figure 4) [10]. Studies on the structure-activity relations showed that inhibitory activity was linked to the substituent in position 6 of the benzopyran ring and was modulated by the size of lipophilic substituents in position 2. These compounds act in a noncompetitive fashion.<smiles>[R]C1Oc2ccc(OCCCCCCC(C)C(=O)OCC)cc2C=C1c1nccn1C</smiles>

$\mathrm{R}=\mathrm{H}$, alkyl, aralkyl, $\mathrm{Ph}, 3-\mathrm{Py}$ etc.

Figure 4. 2,6-Disubstituted 3-(imidazol-2-yl)benzopyran representatives of ACAT inhibitors (10)

3-Pyridinylchroman derivatives 11a,b which posess anti-estrogenic activity, process for their preparation (via 12a,b) (Scheme 4) and a 
method of treating breast cancer have been

claimed [11].

LDA,<smiles>COC(=O)c1ccc(OC)cc1O</smiles>

12a $X=H, Y=N \quad 12 b \quad X=N, Y=H$

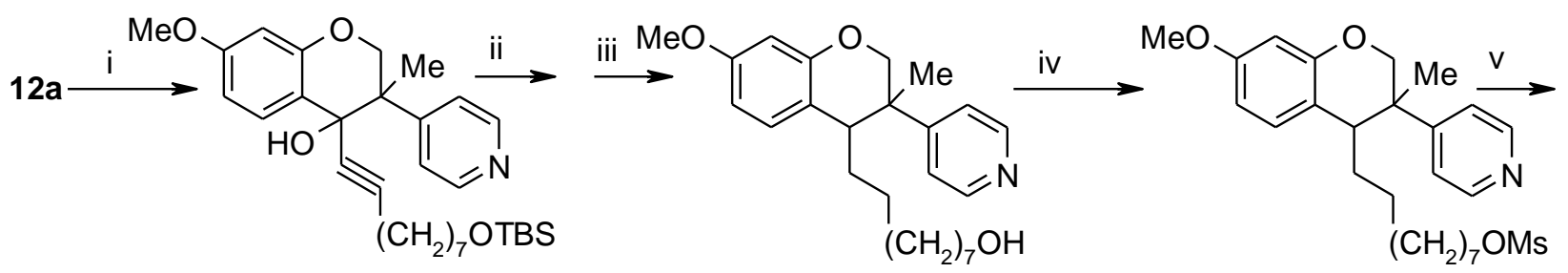

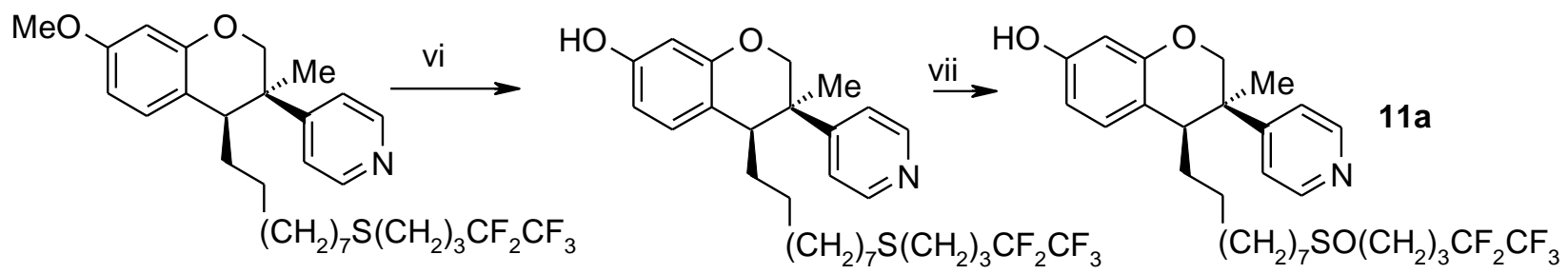

i $\mathrm{HC} \equiv \mathrm{C}\left(\mathrm{CH}_{2}\right)_{7} \mathrm{OTBS}, \mathrm{n}-\mathrm{BuLi}, \mathrm{THF}$

ii $\mathrm{ZnI}_{2}, \mathrm{NaBH}_{3} \mathrm{CN}, \mathrm{ClCH}_{2} \mathrm{CH}_{2} \mathrm{Cl}$; iii $\mathrm{Pd}(\mathrm{OH})_{2}, \mathrm{H}_{2}, \mathrm{AcOEt}$, EtOH, heating iv $\mathrm{MsCl}, \mathrm{Et}_{3} \mathrm{~N}, \mathrm{CH}_{2} \mathrm{Cl}_{2}$

v $\mathrm{AcS}\left(\mathrm{CH}_{2}\right)_{3} \mathrm{CF}_{2} \mathrm{CF}_{3}, \mathrm{NaOMe}, \mathrm{THF}-\mathrm{MeOH}$; vi $\mathrm{BBr}_{3}, \mathrm{CH}_{2} \mathrm{Cl}_{2}$; vii Oxone, THF- $\mathrm{H}_{2} \mathrm{O}$

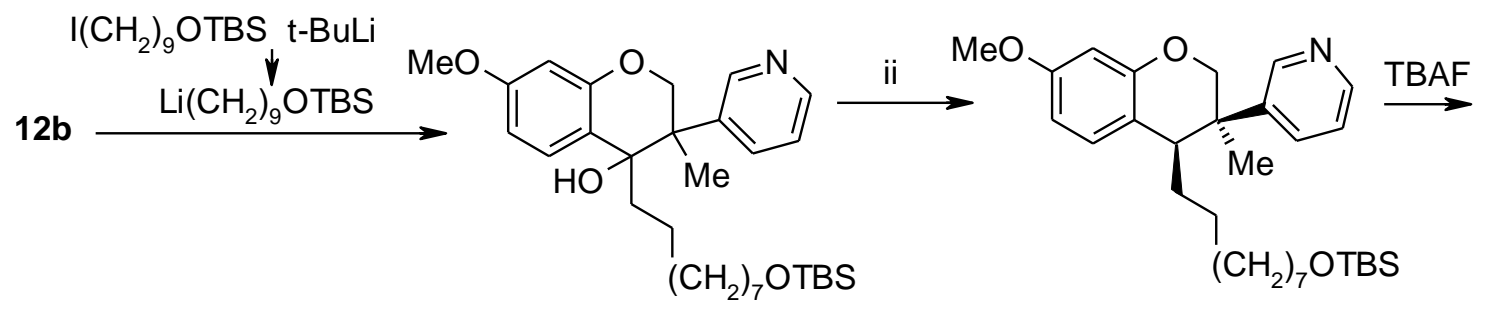<smiles>CCC[C@H]1c2ccc(OC)cc2OC[C@]1(C)c1cccnc1</smiles>

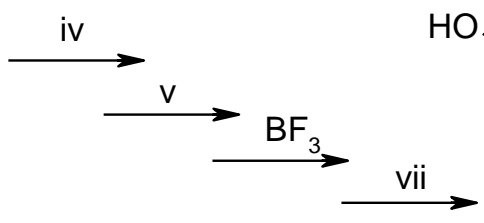<smiles>CCC[C@H]1c2ccc(O)cc2OC[C@]1(C)c1cccnc1</smiles>

$11 b$

Scheme 4. (3RS,4RS)-7-Hydroxy-3-methyl-4-[9-(4,4,5,5-pentafluoropentylsulfinyl)nonyl]-3-(4-pyridyl)- and 3-(3pyridyl)chromans, which posess anti-estrogenic activity 


\section{3-Azahetarylchroman-4-ones conversion} products in reactions with nucleophiles

In general, chroman-4-one derivatives readily react with hydroxylamine, hydrazines, semicarbazides, thiosemicarbazides and other hydroxylamine- and hydrazine-derived reactants. Indeed, these type of reactions are Schiff base reaction which result in $\mathrm{C}=\mathrm{N}$ formation. Isoflavanone Schiff bases of various structures have been patented as therapeutic agents for the treatment, prevention or amelioration of diseases associated with aberrant cell survival, aberrant cell proliferation, abnormal cellular migration, abnormal angiogenesis and estrogen/androgen balance, dysfunctional steroid genesis, degeneration including degenerative changes within blood vessel walls, inflammation and immunological imbalance [12]. Substituted N,N-dimethylaminoalkyl ethers of isoflavanone oxime have been claimed as H1- receptor antagonists [13]. Benzoxazepine derivatives, obtained by isoflavanone oximes transformation, have been patented as selective estrogen receptor modulators [14].

\subsection{C-4 modified 3-azolylchroman-4-ones}

\subsubsection{Synthesis of 3-azolylchroman-4-one oxime derivatives}

Fungal infections cause a persistent burden on human and animal health, plants and agricultural economy [15]. This rising incidence of fungal infections along with the development of resistance to current antifungal therapeutics continues to drive the search for more effective new agents. Among the different classes of antifungal agents (arylalkyl)azoles are the first-line drugs for the treatment of invasive fungal infections, because of their high therapeutic index, acting as sterol biosynthesis inhibitors in fungi [16] (Figure 5). The examination of the structure of well-established drugs for the treatment of many mycotic infections reveals the presence of one common pharmacophore structure, which is characterized by a phenyl ring linked by an ethane chain to a nitrogen of azole ring (imidazol, $\mathrm{A}=\mathrm{CH}$, or triazole, $\mathrm{A}=\mathrm{N}$ ) [17]. The ethane chain is often substituted on its C- 2 by different groups: by ether group, as in miconazole; by the 1,3-spirodioxolane ring, as in ketonazole, or oxime ether group, as in oxiconazole. The role of the oxime group has already been examined in other fungicides and antifungal agents [18, 19]. Some azolylmethylchromanone derivatives were reported to posses antifungal activity [20, 21]. In view of the above observation and in quest to develop new azole antifungals Emami S. et al. have designed and synthesized a few series of 3-azolylchroman-4-one oximes (structure A) and oxime ethers (structure B) as conformationally constrained or cyclic analogs of well-established (arylalkyl)azole antifungals (Figure 5). 
<smiles>CC(=O)N1CCN(c2ccc(OCC3COC(Cn4ccnc4)(c4ccc(Cl)cc4Cl)O3)cc2)CC1</smiles>

ketoconazole<smiles></smiles>

Antifungals<smiles>O=C(OCCOCCO)c1ccc(F)cc1F</smiles><smiles>Clc1ccc(COC(Cn2ccnc2)c2ccc(Cl)cc2Cl)c(Cl)c1</smiles>

miconazole<smiles>[R]c1ccc(C([R])([R])Cn2cncn2)c([R])c1</smiles>

$\mathrm{R}^{1}=\mathrm{OH}, \mathrm{OR}, \mathrm{R}, \mathrm{Ar} \quad \mathrm{R}^{2}=\mathrm{H}$

$R^{1}+R^{2}=1,3$-spirodioxolane ring, $=\mathrm{N}-\mathrm{OR}$

$\mathrm{R}=\mathrm{Cl}, \mathrm{F}$

$\mathrm{A}=\mathrm{CH}, \mathrm{N}$

common pharmacophoric structure of azole untifunguls<smiles>[R]c1cccc(CON=C2c3ccc([R])cc3OC(C)C2[Y10])c1</smiles><smiles>ClC(=Cn1cncn1)c1ccc(Cl)cc1Cl</smiles>

Ioreclezole<smiles>O=C(Cn1ccnc1)c1ccc2ccccc2c1</smiles>

nafimidone<smiles>OC(Cn1ccnc1)c1ccc(-c2ccccc2)cc1</smiles>

denzimole

anticonvulsants

Figure 5. Antifungals, anticonvulsants and their conformationally constrained analogs 
Two stereoselective synthetic pathways were used to obtain the (E)- and (Z)-3azolylchroman-4-one oximes [22-24].<smiles>CCC(CO)C(=O)OCCCCCC(=O)c1ccc(P)cc1O</smiles>

$\mathrm{R}=\mathrm{H}, \mathrm{Cl}$

Het= a $-\underbrace{-N}$

$b-N_{N}^{N} \overbrace{N}$

$c-\underbrace{-N}$
3-Azolylchroman-4-ones 13a-c were converted to the pure (Z)-oxime derivatives $(Z)$-14a-c in good yields by stirring with 3-equiv. of $\mathrm{HONH}_{2} * \mathrm{HCl}$ in methanol, as illustrated in Scheme 5. (E)-3-Azolylchroman-4-one oximes $(\boldsymbol{E})$-14a-c were synthesized from (Z)-3bromochroman-4-one oxime (Z)-15]. Nucleophilic substitution of bromine in compound (Z)-15 by imidazole in DMF or 1,2,4-triazole in the presence of $\mathrm{K}_{2} \mathrm{CO}_{3}$ in $\mathrm{MeCN}$ at room temperature afforded compounds $(E)$-14a-c (Scheme 6).

(Z)- 14a-c (65-98\%)

Scheme 5. The synthesis of (Z)-3-azolylchroman-4-one oximes

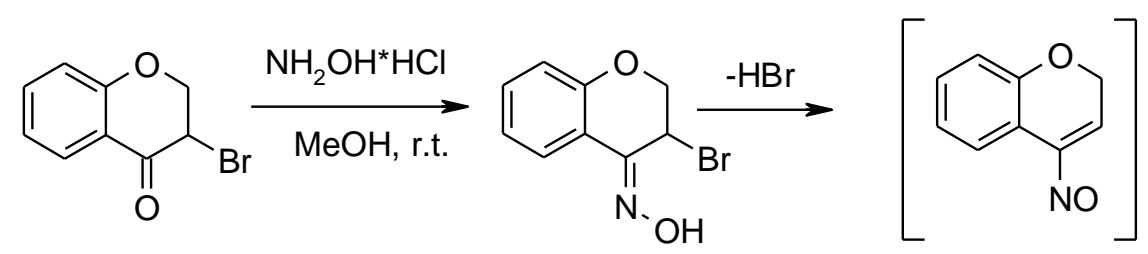

(Z)-15 (93\%)<smiles>CN(C)O[C@H]1COc2ccccc2C1=NO</smiles>

$(E)-14 c(8 \%)$

$(E)-\mathbf{1 4 b}(54 \%)$

(E)-14a (74\%)

Scheme 6. The synthesis of (E)-3-azolylchroman-4-one oximes

trans-3-Azolyl-2-methylchroman-4-one oximes (Z)-16a-c were synthesized from the corresponding

trans-3-azolyl-2-methylchroman-4-ones 17a-c to investigate the 
influence of a methyl group at position 2 on chroman nucleus and to optimize the structure-activity relationships (Scheme 7) $[25,26]$.<smiles>CCC(=O)c1ccc(P)cc1O</smiles>

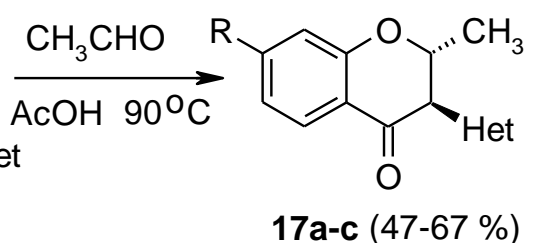

$\mathrm{R}=\mathrm{H}, \mathrm{Cl}$<smiles>[13CH3]n1ccnc1</smiles><smiles>[B]n1cncn1</smiles><smiles>Cn1cnnc1</smiles><smiles>CC1Oc2c(CNO)ccc(c2O)C1=NO</smiles>

(Z)- $16 \mathrm{a}-\mathrm{c}(79-83 \%)$

Scheme 7. The synthesis of (Z)-trans-3-azolyl-2methylchroman-4-one oximes

Previously, Ji et al. designed 2alkylchromanone and their oximes as nonazole inhibitors of 14a-demethylase [27].

In new study [28], S. Emami et al. incorporated imidazole ring on the 3-position of 2-alkylchromanones to design new inhibitors of $14 \alpha$-demethylase and potential antifungal agents. It is speculated that the chroman ring having the 2-alkyl side chain in compounds A (Scheme 8) might be a mimetic of $\mathrm{B}$ and $\mathrm{C}$ rings or $\mathrm{D}$ ring and 17-alkyl side chain of the lanosterol and that the 3imidazolyl residue of $\mathbf{A}$ fills the position of the 14-methyl group of lanosterol for coordination binding to the heme of lanosterol $14 \alpha$-demethylase.

Thus, a series of 2-alkyl-3imidazolylchromanones 18a-g were synthesized by cyclization of $\mathrm{N}-(2-$ hydroxyphenacyl)imidazole derivative with (un)linea aliphatic aldehydes in refluxing 2propanol, in the presence of piperidine as a catalyst ( Scheme 8. The oily crude products (19a-g) were trans-stereoisomers, which underwent nitrate salt formation by using nitric acid in diethyl ether. The 2-alkyl-3imidazolylchromanone nitrates (18 a-g) were obtained as a pure crystalline products. For preparation of oxime derivatives $20 \mathrm{a}-\mathbf{g}$, the crude products $(19$ a-g) were treated with excess hydroxylamine hydrochloride in methanol at room temperature. In this reaction, the addition of $\mathrm{K}_{2} \mathrm{CO}_{3}$ assisted to the reaction completion. The oxime products (20a-g) were assigned as (Z)-transstereoisomers. The experimental data based on ${ }^{1} \mathrm{H}$ NMR spectroscopy revealed that 2 alkyl side chain and 3-imidazolyl moiety in compound $\mathbf{1 8 d}$ exist predominantly in the diequatorial conformation. While docking study with $14 \alpha$-demethylase demonstrated that the di-axial form of compound 18d can be considered as active conformation. 


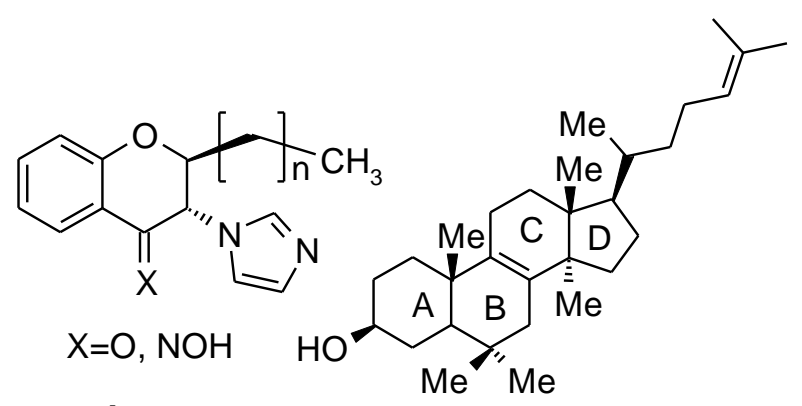

A

Lanosterol

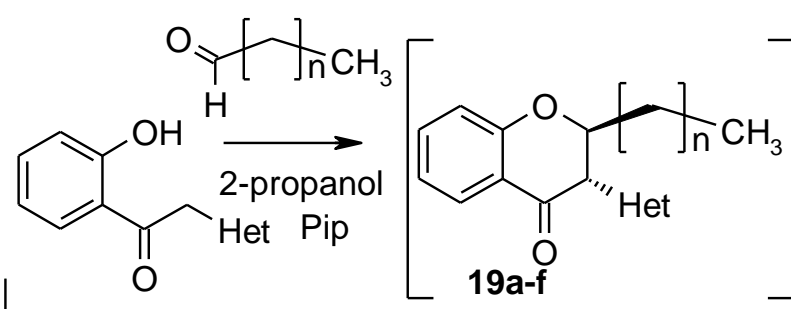<smiles>C=C1OC(CC(C)(C)C)[C@H](CC(C)C)C(=O)C1=C</smiles>

18a-f $(25-52 \%)$

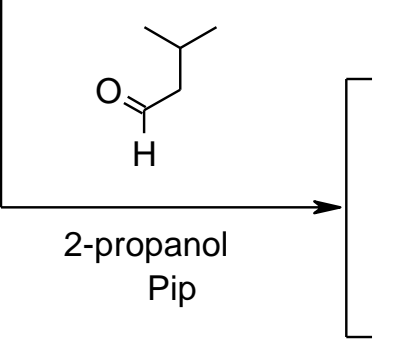

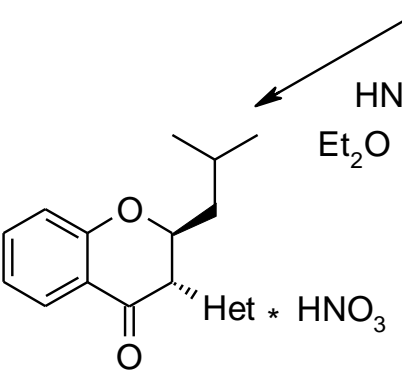

$18 \mathrm{~g}(40 \%)$
$19 \mathrm{~g}$

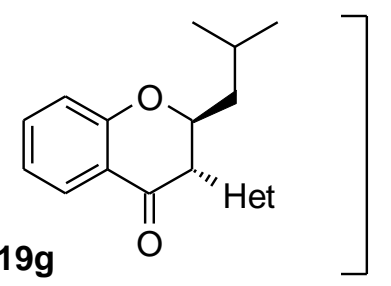

$\mathrm{HNO}_{3}$

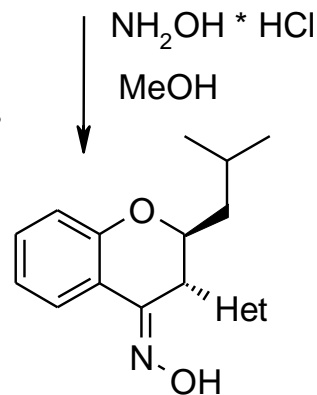

$20 \mathrm{~g}(50 \%)$
Scheme 8. The synthesis of (Z)-trans-3-(imidazol-1yl)-2-alkylchroman-4-one oximes<smiles>O=C(Cn1cncn1)c1ccccc1O</smiles>

$21(54-85 \%)$<smiles>[R2]c1ccc([C@@H]2Oc3ccccc3C(=NO)[C@@H]2n2ccnc2)cc1</smiles>

(a) $\mathrm{NH}_{2} \mathrm{OH}^{*} \mathrm{HCl}, \mathrm{K}_{2} \mathrm{CO}_{3}, \mathrm{MeOH}$, r.t. $\mathrm{X}=\mathrm{CH}(77-96 \%)$ $\mathrm{X}=\mathrm{N}$ unknown degraded products

(b) $\mathrm{NH}_{2} \mathrm{OH}^{*} \mathrm{HCl}, \mathrm{MeOH}$, reflux $\quad \mathrm{X}=\mathrm{N}(79-81 \%)$

Scheme 9. The synthesis of 3-azolylflavanone oximes

In the research field of azole antifungal agents investigations with a flavan core have been reported [29]. A series of new trans-3azolyl-flavans containing 4 oxo (21) or (Z)-4hydroxyimino (22) functional groups on the flavan ring were synthesized chemo- and stereoselectively, as potential antifungal agents [30-32]. The synthetic pathway to target compound is the reaction of 2-azolyl2'-hydroxyacetophenone with different benzaldehyde derivatives and subsequence oximation reaction (Scheme 9). The trans-3azolylflavanones $\mathbf{2 1}$ were obtained in good yields (except compound $21(X=N, R=4-F)$ without using chromatography under fairy mild reaction conditions tolerating various functional groups. The results showed that 0.33 equivalents of piperidine as catalyst in refluxing 2-propanol had good activity and 
very high selectivity to trans-3azolylflavanones, while the use of acid medium decreased the catalytic activity and flavanone selectivity because of the production of equilibrium position between the four potential products $(E-$ and $Z$ chalcones and cis- and trans-flavanones). It is for this reason, the reaction of 2-imidazolyl2 '-hydroxyacetophenone and benzaldehyde in equimolar quantities in $\mathrm{AcOH}$ at $90^{\circ} \mathrm{C}$ for 12 hours or in an excess of benzaldehyde at 110$120^{\circ} \mathrm{C}$ for 10 hours have proved unsuccessful and the target trans-3-imidazolylflavanone $\mathbf{2 1}$ $(\mathrm{X}=\mathrm{CH}, \mathrm{R}=\mathrm{H})$ was obtained with very low yields $12 \%$ and $14 \%$ respectively [32].

\subsubsection{Synthesis of 3-azolylchroman-4-one oxime ethers}

$O$-Alkylation of (E)- and (Z)- 3azolylchroman-4-one oximes $(\boldsymbol{E}),(Z)-14 a-c$ with substituted benzylhalides $\mathbf{2 3}$ in the presence of $\mathrm{K}_{2} \mathrm{CO}_{3}$ in DMF at $50^{\circ} \mathrm{C}$ (for $(Z)$ 14a,c) or in DMF in the presence of $\mathrm{NaH}$ at room temperature (for $(Z)-\mathbf{1 2 b}$ and $(E)-\mathbf{1 4 a - c}$ ) gave the corresponding (E)- and (Z)-3azolylchroman-4-one oxime ethers $(\boldsymbol{E})$-24a-c and (Z)-24a-c (Method A) (Scheme 10). Alternatively, the $o$-substituted oximes could directly be obtained from the corresponding 3-azolylchroman-4-ones 13a-c (Method B). The treatment of the latter with $o$ (arylmethyl)hydroxylamines $\mathbf{2 5}$ in methanol afforded a mixture of (Z)- and (E)-oxime ethers $(\boldsymbol{Z}),(\boldsymbol{E})$-24a-c, predominantly in the $\mathrm{Z}$ configuration, which was established by ${ }^{1} \mathrm{H}$ NMR spectra data. The Z/E ratio was approximately 90:10 (examples for 1,2,4triazolyl derivatives: $(\boldsymbol{Z}),(\boldsymbol{E})-\mathbf{2 4 b} \quad\left(\mathrm{R}^{1}=\mathrm{H}\right.$, $\left.\mathrm{R}^{2}=4-\mathrm{Cl}\right)-66 \%(\boldsymbol{Z})-\mathbf{2 4 b}$ and $8 \%(\boldsymbol{E})-\mathbf{2 4 b}$; $(Z),(E)-24 c\left(\mathrm{R}^{1}=\mathrm{Cl}, \mathrm{R}^{2}=2,4-\mathrm{Cl}_{2}\right)-46 \%(Z)-$ $\mathbf{2 4 c}$ and $5 \%(\boldsymbol{E})-\mathbf{2 4 c}$ as a free base). In most cases in the work up of the crude products of imidazolyl derivatives $(\boldsymbol{Z}),(\boldsymbol{E})-\mathbf{2 4 a}$ led to the practically pure $(Z)$-oxime ethers in moderate yields ( $(Z)-24 a\left(\mathrm{R}^{1}=\mathrm{R}^{2}=\mathrm{H}\right)$ - 51\%; $(\mathbf{Z})-\mathbf{2 4 a}$ $\left.\left(\mathrm{R}^{1}=\mathrm{Cl}, \mathrm{R}^{2}=3,4-\mathrm{Cl}_{2}\right)-45 \%\right)$.

Both synthetic pathway (methods A and B) were used to target (Z)-trans-3-azolyl-2methylchroman-4-one oxime ethers $(\boldsymbol{Z})$-26-ac, which were obtained in generally good yields (45\%-82\%) (Scheme 11). 


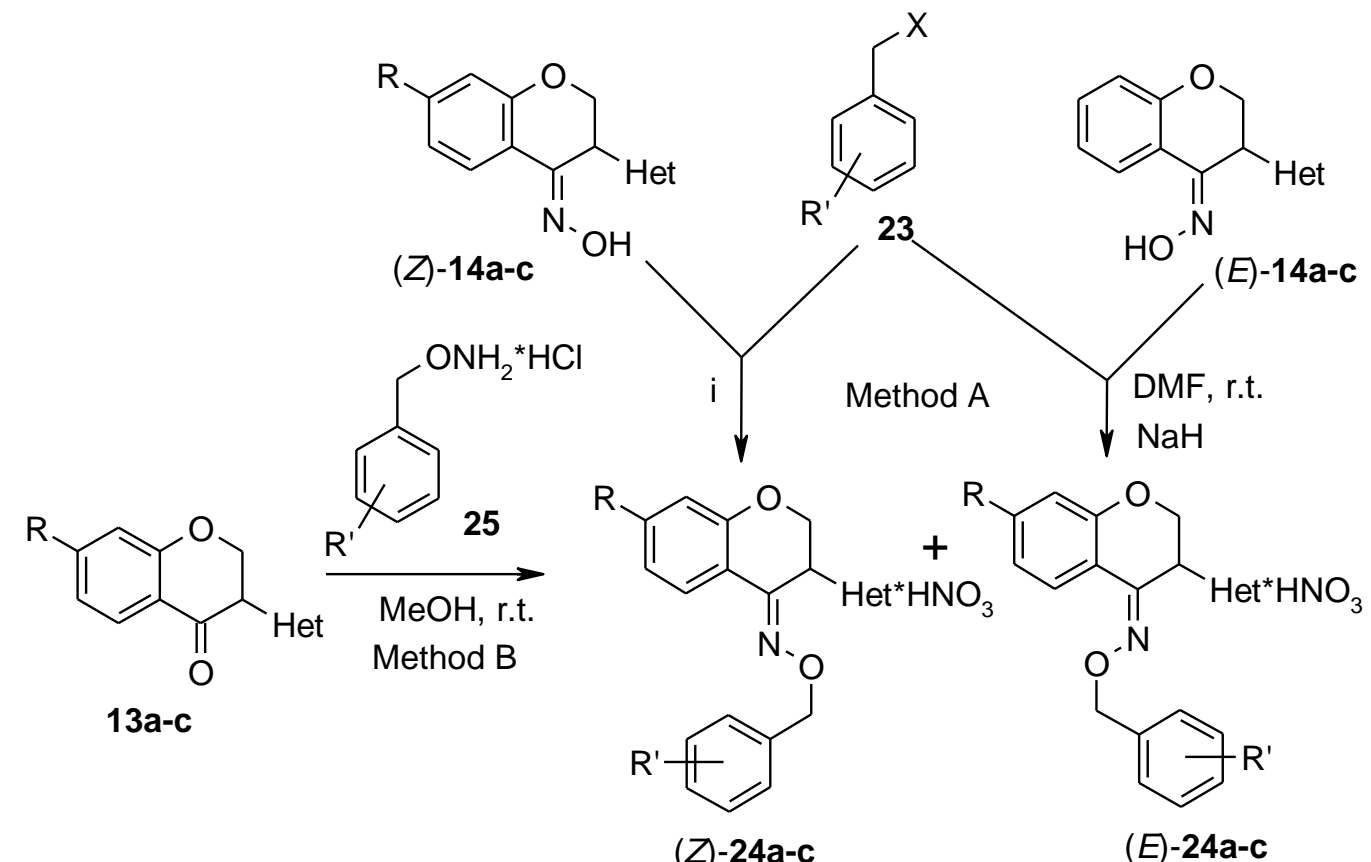

$\mathrm{R}=\mathrm{H}, \mathrm{Cl} ; \mathrm{X}=\mathrm{Br}, \mathrm{Cl} ; \mathrm{R}^{\prime}=\mathrm{H}, 4-\mathrm{Cl}, 4-\mathrm{Br}, 4-\mathrm{F}, 3-\mathrm{F}, 2-\mathrm{F}, 2,4-\mathrm{Cl}_{2}, 3,4-\mathrm{Cl}_{2}, 2,6-\mathrm{Cl}_{2}$

i (a,c) $\mathrm{K}_{2} \mathrm{CO}_{3}, \mathrm{DMF}, 50^{\circ} \mathrm{C}$

i (b) NaH DMF, r.t.

Scheme 10. The synthesis of isomeric (E)- and (Z)-3-azolylchroman-4-one oxime ethers

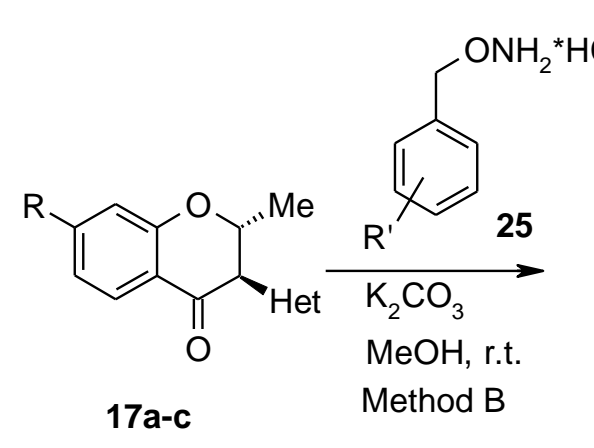<smiles>c1ccc2c(c1)CCCC2</smiles><smiles>[X]Cc1cccc([R])c1</smiles>

Method A<smiles>[R]c1ccc2c(c1)OC(C)[C@H](Cl)/C2=N\O</smiles>

$(Z)-16 a-c$

(Z)-26a-c

$\mathrm{R}=\mathrm{H}, \mathrm{Cl} ; \mathrm{X}=\mathrm{Br}, \mathrm{Cl} ; \mathrm{R}^{\prime}=\mathrm{H}, 4-\mathrm{Cl}, 4-\mathrm{Br}, 4-\mathrm{F}, 3-\mathrm{F}, 2-\mathrm{F}, 2,4-\mathrm{Cl}_{2}$, 3,4- $\mathrm{Cl}_{2}, 2,6-\mathrm{Cl}_{2}$

Scheme 11. Stereoselective synthesis of (Z)-trans-3-azolyl-2-methylchroman-4-one oxime ethers

The configuration of the oximes (Z)-14a-c, the $(E)$ - and $(Z)$-isomers of oximes and oxime $(E)$-14a-c and oxime ethers $(\boldsymbol{Z}),(E)-24 a-c$ and ethers. $(E)$-Oximes 14a-c showed a signal at (Z)-26a-c was assigned by ${ }^{1} \mathrm{H}$ NMR $5.26-5.44 \mathrm{ppm}$ for H-3. In contrast (Z)-oximes spectroscopy. Chemical shifts of the H-3 and H- 14a-c exhibited the H-3 signal at the lower field 5 protons of the chroman ring are different in $5.87-6,04 \mathrm{ppm}$, due to the deshielding effect of 
the hydroxyl group on the H-3. On the other hand, the chemical shift of H-5 of $(\boldsymbol{E})-\mathbf{1 4 a}-\mathrm{c}$ is influenced by the hydroxyl group and the signal appeared downfield at $8.70 \mathrm{ppm}$, whereas those of the (Z)-isomers (Z)-14 a-c showed the same signal at 7.85-7.87 ppm. Similar results were observed in the ${ }^{1} \mathrm{H}$ NMR of the oxime ethers $(Z)$ - and (E)-24a-c.

Thus, the configurational assignment of the oxime geometry was simple due to the strong anisotropic deshielding by the oxime oxygen on the $\mathrm{H}-3$ or $\mathrm{H}-5$ proton on chroman ring. Structural characterization of trans-2-methyl-3(1,2,4-triazolyl)chroman-4-one oxime ethers has been achieved [26]. By analysis of vicinal interproton coupling constants, it is believed that trans-2-methyl-3-(1,2,4-triazolyl)chroman4-ones which exist predominantly in the diequatorial half-chair or sofa conformation was found to exist predominantly in the diaxial orientation upon conversion to the corresponding oxime ether derivatives.

Besides azole antifungals with benzyl ether side chains, omoconazole is a distinct azole antifungal with non-benzylic side chain namely 2-(4-chlorophenoxy) ethyl ether. In continuation of research program on azole antifungals, modifications on the side chains of imidazolylchromanone oxime ethers was focused, and 2-phenoxyethyl ether moiety was attached to the imidazolylchromanone oxime scaffold instead of benzyl ether residue [33].<smiles>C/C(=C(/OCCOc1ccc(Cl)cc1)c1ccc(Cl)cc1Cl)n1ccnc1</smiles><smiles>[R]c1cccc(OCC[AlH2])c1</smiles>

14

1. $\mathrm{NaH}, \mathrm{DMF}$ 2. $\mathrm{i}-\mathrm{PrOH}, 65 \% \mathrm{HNO}_{3}$<smiles></smiles>

$\mathrm{R}=\mathrm{H}, 4-\mathrm{Cl}, 3-\mathrm{Cl}, 4-\mathrm{F}, 3-\mathrm{F}, 2,4-\mathrm{Cl}_{2}$

Scheme 12. Synthesis of imidazolylchromanone O(phenoxyethyl) oxime ethers.

The synthesis of target imidazolylchromanone $O$-(phenoxyethyl)- oxime ethers is outlined in Scheme 12. (E)-oxime 14 was reacted with phenoxyethyl chloride derivatives 27a-f in the presence of $\mathrm{NaH}$ in DMF to give $(E)$-oxime ether derivatives 28a-f. The structures of compounds 28a-f were fully characterized by IR, ${ }^{1} \mathrm{H}$ NMR, ${ }^{13} \mathrm{C}$ NMR and MS spectral data. 
2.1.3. Biological activities of 3- $\left.\mathrm{R}^{\prime}=4-\mathrm{Cl}\right),(\boldsymbol{Z})-\mathbf{2 4 b}\left(\mathrm{R}=\mathrm{H}, \mathrm{R}^{\prime}=4-\mathrm{Br}\right)$ and $(\mathbf{Z})$ azolylchroman-4-one oxime and oxime ether derivatives

\subsubsection{Antifungal activity}

A series of $(E)$ - and (Z)-3-(1H-imidazol-1yl)chroman-4-one oxime ethers $\mathbf{2 4 a}$ have been tested for antifungal activity against pathogenic fungi. Oxiconazole and miconazole were used as reference drugs. Most compounds showed moderate to potent in vitro antifungal activity. Among the tested compounds, compound $(\boldsymbol{E})$ 24a $\left(\mathrm{R}=\mathrm{H}, \mathrm{R}^{\prime}=3,4-\mathrm{Cl}_{2}\right)$ was the most active agent against Candida albicans and Aspergillus niger and compounds (Z)- and (E)-24a $\left(\mathrm{R}=\mathrm{R}^{\prime}=\mathrm{H}\right)$ were the most potent compounds against Microsporum gypseum. The position and number of chlorine atoms at $O$-benzyl group and chlorine atom linked to the 7 position of chroman ring seemed to have different influence on the antifungal activity against various fungi strains. Among the test strains, only against Aspergillus niger, a good correlation between activity and the geometry of oxime group was observed [ 24].

The results of antifungal evaluation of the test 1,2,4-triazolylchromanone oxime ethers 24b,c indicated that the compound $(Z)-\mathbf{2 4 b}(\mathrm{R}=7-\mathrm{Cl}$, $\mathrm{R}^{\prime}=2,4-\mathrm{Cl}_{2}$ ) was the most potent against the yeasts, compounds $(\boldsymbol{E})-\mathbf{2 4 b}\left(\mathrm{R}=\mathrm{H}, \mathrm{R}^{\prime}=4-\mathrm{Cl}\right)$ and $\quad(\boldsymbol{E})-\mathbf{2 4 b} \quad\left(\mathrm{R}=\mathrm{H}, \quad \mathrm{R}^{\prime}=4-\mathrm{Br}\right) \quad$ showed comparable or more potent antifungal activity with respect to fluconazole against all tested fungal species. Compounds (Z)-24b $(\mathrm{R}=\mathrm{H}$,

24b $\left(\mathrm{R}=\mathrm{H}, \mathrm{R}^{\prime}=3-\mathrm{F}\right)$ showed comparable or more potent antifungal activity with respect to fluconazole except for antifungal activity against $C$. albicans. Compounds (E)-24b $\left(\mathrm{R}=\mathrm{R}^{\prime}=\mathrm{H}\right), \quad$ and $(\boldsymbol{E})-\mathbf{2 4 b} \quad\left(\mathrm{R}=\mathrm{H}, \quad \mathrm{R}^{\prime}=3,4-\mathrm{Cl}_{2}\right)$ showed comparable or more potent antifungal activity with respect to oxiconazole except for antifungal activity against $S$. cerevisiae. In terms of structure-activity relationship, the 1,2,4-triazol-1-yl derivatives 24 b showed more potent antifungal activity than 1,2,4-triazol-4-yl derivatives 24c. In general, imidazolyl and 1,2,4-triazol-1-yl chromanone oxime ethers 24 have a similar biological profile and structureactivity relationships but 1,2,4-triazol-1ylchromanone oxime ethers showed lower in vitro antifungal activity than imidazolylchromanone oxime ethers [23]

The results of biological tests for antifungal activities of 3-azolyl-2-methylchromanone oxime ethers 26a-c [25, 26] demonstrated that the introduction of methyl group at 2-position of chroman ring in azolylchromanone oxime ethers improved the overall antifungal activity.

Nevertheless, the effect of methyl group dependent on the other substituents. Many of the title compounds showed high activity against all tested fungi. Among target compounds, (Z)-trans-7-chloro-3-imidazolyl-2methylchromanone oxime ether derivative $\mathbf{2 6 a}$ $\left(\mathrm{R}=7-\mathrm{Cl}, \mathrm{R}^{\prime}=\mathrm{H}\right)$ with MIC values of $0.25,0.5$ and $1 \mu \mathrm{g} / \mathrm{mL}$ against $C$. albicans, $S$. cerevisiae 
and M. gypseum, showed the highest activity. This derivative was 32-64 times more potent than fluconazole and was the most potent among the studied 2-methyl series 26a-c. and nonmethyl substituted series 24a-c. Compound 26a $\left(\mathrm{R}=\mathrm{H}, \mathrm{R}^{\prime}=4-\mathrm{F}\right)$ was the most potent compounds against $M$. gypseum (MICs =1 $\mu \mathrm{g} / \mathrm{mL})[25]$.

The antifungal activity of 2-alkyl-3imidazolylchroman derivatives 18a-g and 20a-g [28] were evaluated against $C$. albicans, $S$. cerevisiae (yeast), M. gypseum (dermatophyte) and $A$. niger (mould). In the case of $C$. albicans and S. cerevisiae trans-2-(1-pentyl)-3imidazolylchroman-4-one (18d) showed the most potent activity against yeasts with MIC values of $8 \mu \mathrm{g} / \mathrm{mL}$ comparable to fluconazole. Compound 18f $\left(2-\mathrm{C}_{7} \mathrm{H}_{15}\right)$ showed good ingibitory activity (MICs=8-16 $\mu \mathrm{g} / \mathrm{mL}$ ) against yeasts comparable to fluconazole. Furthermore, compounds 18c $\left(2-\mathrm{C}_{4} \mathrm{H}_{9}\right)$, 18e $\left(2-\mathrm{C}_{6} \mathrm{H}_{11}\right), 20 \mathrm{c}$ $\left(2-\mathrm{C}_{4} \mathrm{H}_{9}\right)$ and $20 \mathbf{d}\left(2-\mathrm{C}_{5} \mathrm{H}_{11}\right)$ were active against yeasts with MIC values of $16-64 \mu \mathrm{g} / \mathrm{mL}$. Although, fluconazole was inactive against $\mathrm{M}$. gypseum and A. niger (MICs $>64 \mu \mathrm{g} / \mathrm{mL}$ ), but compounds $\mathbf{1 8 d}-\mathbf{f}\left(2-\mathrm{C}_{5}-2-\mathrm{C}_{7}\right), \mathbf{2 0 a}\left(2-\mathrm{C}_{2} \mathrm{H}_{5}\right)$, 20c-e $\left(2-\mathrm{C}_{4}-2-\mathrm{C}_{6}\right)$ and $20 \mathrm{~g}$ (2-izobutyl) exhibited mild activity against these fungi. The imidazolylchromanones (18a-c and 18g) containing small side chain $\left(\mathrm{C}_{1}-\mathrm{C}_{4}\right)$ were inactive. While chromanones bearing longer 2alkyl group $\left(>\mathrm{C}_{4}\right)$ showed better antifungal activity against all fungi strains tested. The comparison of chromanone compounds (18) with related oxime derivatives demonstrated that oximation had negative effect and diminished the antifungal activity. Also, compounds $18 \mathrm{~g}$ and $20 \mathrm{~g}$ with a branched alkyl group (isobutyl) showed no activity against $C$. albicans, S. cerevisiae and A. niger.

A series [33] of imidazolylchromanone oximes 28a-f containing phenoxyethyl ether moiety were evaluated against yeasts (Candida albicans and Cryptococcus gattii) and filamentous fungi (Aspergillus fumigatus and Exophiala dermatitidis) in comparison with those of parent 3-imidazolyl-4-chromanone oxime (14) and standard drugs fluconazole and itraconazole. The parent oxime $\mathbf{1 4}$ showed no activity against all fungal species. All title compounds 28a-f were inactive against $C$. albicans (MIC values $>64 \mu \mathrm{g} / \mathrm{mL})$. Although the title compounds showed marginal activity against filamentous fungi but all of them exhibited potent activity against $C$. gattii $(\mathrm{MIC}$ values $=0.5-4 \mu \mathrm{g} / \mathrm{mL})$. It could be concluded that the phenoxyethyl ether scaffold is essential for antifungal activity. Although halogen substitution had positive effect in some cases depends on its position, but could not significantly improve antifungal activity. Among target compounds (3chlorophenoxy)ethyl analog $\mathbf{2 8 c}\left(\mathrm{R}^{\prime}=3-\mathrm{Cl}\right)$ with MIC value of $0.5 \mu \mathrm{g} / \mathrm{mL}$ was the most potent compound, 4-8 folds more potent than other halo-substituted congeners against $C$. gattii. Further molecular docking studies provided a 
better insight into the binding of designed compounds within the homology modeled active site of CnCYP51 (Cryptococcus CYP51$14 \alpha$-demethylase).

The results of antifungal activity studies, together with the selectivity displayed by compounds 28a-f against $C$. gattii, introduces new lead compounds in the development of novel azole antifungal drugs for treatment of cryptococcal infections. Cryptococcal infections and specially infections caused by $C$. gattii are life-threatening complications for immunocompromised hosts, producing fatal cryptococcosis in patients who have undergone organ transplants and being the main cause of fatal meningoencephalitis in AIDS patients. Thus the designed compounds acting against this fungal pathogen are highly desirable for further in vivo and clinical studies. Thus, this compound 28c was considered for further molecular and computational analysis.

Most of trans-3-imidazolyl-substituted flavan-4ones 21 and (Z)-trans-3-imidazolyl-substituted flavan-4-one oximes 22 possessed significant antifungal activities against the tested fungi, comparable or superior to fluconazole[31]. The modification of the 4-oxo group to oxime or substituent on phenyl ring produced changes in the antifungal activity profile of these compounds. Generally, in 3-imidazolylflavanone series 3'-chloro- analog $\mathbf{2 1}$ exhibited better profile of antifungal activity against strains of fungi tested, superior than reference drug fluconazole [32].

4'-Fluoro-analog in 3-(1,2,4-triazol-1-yl)flavanone derivative 21 exhibited the best profile of activity against yeasts and was 4-16 times more potent than reference drug fluconazole against Candida albicans and Saccharomyces cerevisiae. The conversion of flavan-4-ones to oximes (compounds 21 vs. compounds 22) could not improve antifungal activity. Among 3-(1,2,4-triazol-1-yl) flavan-4ones 21 compounds containing methyl or methoxy substituents were inactive, while 3'- or 4'-chloro- and 3'- or 4'-fluoro- derivatives showed antifungal activity.

The molecular docking study with lanosterol $14 \alpha$-demethylase, in silico toxicity risks and drug-likeness predictions were used to better define of title compounds as antifungal agents. The favorable drug-like property of compound 21 makes 3-(1,2,4-triazol-1-yl)flavanone prototype as a promising lead for the future development of azole antifungal agents [30].

\subsubsection{Anticonvulsant activity}

A series of 3-azolylchroman-4-one derivatives 13a-c, 14a-c, 16a-c, 17a-c were explored as potential anticonvulsant agents. The anticonvulsant activity of the compounds 13a-c, 14a-c, 16a-c, 17a-c were evaluated by determining seizure latency and protective effect against pentylenetetrazole (PTZ)-induced 
lethal convulsions in mice at a dose of $5 \mathrm{mg} / \mathrm{kg}$ [34].

Among investigated 3-azolylchroman-4-ones

13a-c and 17a-c, 3-(1H-1,2,4-triazol-1yl)chroman-4-one, 7-chloro-3-(1H-imidazol-1yl)chroman-4-one, trans-3-(1H-imidazol-1-yl)2-methylchroman-4-one and trans-7-chloro-3(1H-imidazol-1-yl)-2-methylchroman-4-one exhibited significant action in delaying seizure as well as effective protection against PTZinduced seizure and deaths. The most effective compounds in delaying seizures were 3-(1H1,2,4-triazol-1-yl)chroman-4-one and 7-chloro3-(1H-imidazol-1-yl)chroman-4-one.

Furthermore, compound 7-chloro-3-(1Himidazol-1-yl)chroman-4-one showed the maximum protection against PTZ-introduced mortality. No effective compound was detected in triazol-4-yl series.

It found no effective compounds among 3azolylchroman-4-one oximes. No mortality was detected only with (Z)-3-(1H-imidazol-1yl)chroman-4-one oxime, but this compound afforded no significant protection against HLTE and delaying seizures.

In another study [35], two distinct pharmacological models, lithium pilocarpine induced seizure and PTZ-induced kindling

were used to investigate both anticonvulsive and antiepileptogenic properties of the selected azolylchromanones including 7-chloro-3-(1Himidazol-1-yl)chroman-4-one), triazol-1-yl)chroman-4-one, $3-(1 H-1,2,4-$ trans-3-(1H- imidazol-1-yl)-2-methylchroman-4-one and trans-7-chloro-3-(1H-imidazol-1-yl)-2-methylchroman-4-one in comparison to sodium valproate as reference drug. In spite of potent activity of above-cited compounds in the acute model of PTZ test these compounds had limited activity in PTZ induced kinding model. Among them, 7-chloro-3-(1H-imidazol-1-yl)chroman-4one was found to exert respectable action in delaying seizures and reducing seizure index at the dose of $10 \mathrm{mg} / \mathrm{kg}$. These results were not surprising, because the two sets of models are fundamentally different. On the other hand, all tested compounds were effective in the lithium pilocarpine model of epilepsy. 7-Chloro-3-(1Himidazol-1-yl)chroman-4-one was found to be more effective in delaying seizures as well as decreasing seizure duration in this model. These compounds can be considered as promising and important class of compounds effective against lithium pilocarpine induced status epilepticus, suggesting the potential application of the test compounds in the treatment of status epilepticus. Afterwards (Z)- and (E)-oxime ether derivatives of imidazolylchromanones bearing different lipophilic $O$-benzyl groups 24, 26 were tested for their anticonvulsant activies in PTZkindling model of epilepsy [36]. (Z)-O-(2,4Dichlorobenzyl)oximes $24(\mathrm{R}=7-\mathrm{Cl}, \mathrm{R}$ '=2,4$\left.\mathrm{Cl}_{2}\right), 26\left(\mathrm{R}=\mathrm{H}, \mathrm{R}^{\prime}=2,4-\mathrm{Cl}_{2}\right.$ and $\mathrm{R}=7-\mathrm{Cl}$, $\mathrm{R}^{\prime}=2,4-\mathrm{Cl}_{2}$ ) were significantly effective in delying the onset of the PTZ-evoked seizures at the doze of $30 \mathrm{mg} / \mathrm{kg}$ in kindled animals. The 
most effective compounds in delying seizures were 7-chlorochromanone-O-(2,4-dichlorobenzyl) oximes $24\left(\mathrm{R}=7-\mathrm{Cl}, \mathrm{R}^{\prime}=2,4-\mathrm{Cl}_{2}\right)$ and $26\left(\mathrm{R}=7-\mathrm{Cl}, \mathrm{R}^{\prime}=2,4-\mathrm{Cl}_{2}\right)$.

SAR studies showed that introduction of the chlorine atom to the 7-position and/or a methyl group to the 2-position of the chroman ring resulted in the improvement of anti-seizure efficacy in $O$-(2,4-dichlorobenzyl)oxime series.

\subsubsection{Synthesis of 3-azolylchroman-4-one}

\section{hydrazone derivatives}

In continuation of research work Emami et al. incorporated phenylhydrazone moiety instead of oxime ether fragment in 3-azolylchroman-4-one derivatives [37]. Owing to this modification, based on the structure of zinoconazole, a wellknown azole antifungal possessing phenylhydrazone substructure, 3azolylchroman-4-one phenylhydrazones 29 have been designed and synthesized as new antifungal agents.

The synthesis of hydrazone derivative 29b $(\mathrm{R}=\mathrm{H})$ was first attempted by reaction of 3(1,2,4-triazol-4yl)chroman-4-one 13b with phenylhydrazine hydrochloride in refluxing methanol in the presence of $\mathrm{Na}_{2} \mathrm{CO}_{3}$ as a base, which resulted in poor yield with mixture of unknown degraded products. Since the condensation reactions of amines and hydrazines with ketones are commonly catalyzed by acids or bases, thus the alternative condition was using hydrochloride salt of phenylhydrazine in the absence of a base. Accordingly, the reaction of compound 13a,b and 17a with phenylhydrazine hydrochloride in methanol at room temperature afforded final compounds 29 in a mild condition (Scheme 13). It seems that the acid released by hydrochloride salt of phenylhydrazine is adequate for catalyzing the condensation reaction. Previously, the reaction of chromanone and flavanone derivatives with substituted hydrazines has been investigated in different conditions [38, 39]. Kállay et al. have been reported that the flavanone hydrazones are predominantly obtained under acidic conditions while alkaline conditions give the pyrazolines and the 2-hydroxychalcone derivatives due to the ring cleavage of the hetero ring of chromanone [38].<smiles>Clc1ccc(/C(Cn2ccnc2)=N\Nc2c(Cl)cccc2Cl)s1</smiles><smiles>[R]c1ccc2c(c1)OC([R7])C(n1cncn1)C2=O</smiles>

Scheme 13. The synthesis of 3-azolylchroman-4-one phenylhydrazones 
Similarly, in experiment with 3-azolyl-4chromanones, the hydrazone derivatives were predominantly obtained under mild acidic conditions, but in the presence of weak base $\mathrm{Na}_{2} \mathrm{CO}_{3}$, possibly produced a mixture of corresponding hydrazone, acyclic N-substituted hydrazine and pyrazoline derivatives which was difficult to separate and characterize. The structures of compounds 29 were properly characterized by IR, ${ }^{1} \mathrm{H} \quad \mathrm{NMR}$ or Mass spectroscopy as well as elemental analyses.

\subsubsection{Antifungal activity of 3-} azolylchroman-4-one hydrazone derivatives

The in vitro antifungal activity of compounds $\mathbf{2 9}$ revealed that all compounds showed good antifungal activity against Candida albicans, Saccharomyces cerevisiae and Microsporum gypseum with MIC values of $8-16 \mu \mathrm{g} / \mathrm{mL}$. The antifungal activity of title compounds was comparable to that of standard drug fluconazole $(\mathrm{MIC}=8-32 \mu \mathrm{g} / \mathrm{mL})$. Parent 2-methyl-3imidazolylchroman-4-one (17a) showed no activity against Saccharomyces cerevisiae, Aspergillus niger and Microsporum gypseum ( $\mathrm{MIC}>64 \mu \mathrm{g} / \mathrm{mL}$ ) and weak activity against Candida albicans. The results of antifungal assay and docking study revealed that the introduction of phenylhydrazone moiety on the chroman ring improves the antifungal activity against all strains. The 2-methyl-3-imidazolyl derivative 29'a which showed the highest druglikeness and drug-score values serves as a lead for future development of antifungal agents. Docking study, in silico toxicity risks and druglikeness predictions were used to better define of title compounds as antifungal agents.

The comparison of MIC values of triazole derivative 29b with its $O$-benzyloxime ether counterpart demonstrates that replacement of $O$ benzyloximino moiety with hyrazone can increase antifungal potency. However, in the cases of imidazol derivatives 29a and 29'atheir $O$-benzyloximino analogs have a better profile of antifungal activity.

2.2. Conformationally constrained analogs of $\mathrm{N}$-(phenethyl)piperazinyl quinolones

\section{2,2,1. Synthesis of N-(2,3-dihydro-4- hydroxyimino-4H-1-benzopyran-3-yl)- piperazinyl quinolones}

Because of increasing prevalence of bacterial infections, drug-discovery efforts have been intensified to search for more effective and safety antibacterial agents with a broad spectrum of activity and activity against resistant pathogens. It is known that fluoroquinolones are among the most attractive agents in the treatment of bacterial infections. The presence of a piperazinyl substituent at the C-7 position of the quinolone nucleus improves the ability of the fluoroquinolones to penetrate the bacterial cell wall, thereby boosting its activity against Gram-negative bacteria and providing some degree of Gram-positive activity. In ongoing antibacterial research program, Emami et al. have recently developed 
new quinolone antibacterials 34 (Figure 6) derived from a piperazinyl quinolone nucleus (norfloxacin 30, enoxacin 31, ciprofloxacin 32, and levofloxacin 33) bearing 2-hydroxyimino-2-phenylethyl moieties at the $\mathrm{N}-4$ position of the piperazine ring and displaying in vitro activity against Gram-positive et al.<smiles>[Y]c1c(N2CCNCC2)c(F)cc2c(=O)c(C(=O)O)cn([R])c12</smiles>

30 norfloxacin $\mathrm{R}=\mathrm{Et}, \mathrm{X}=\mathrm{CH}$ 31 enoxacin $\mathrm{R}=\mathrm{Et}, \mathrm{X}=\mathrm{N}$ 32 ciprofloxacin $\mathrm{R}=$ cyclo- $\mathrm{Pr}, \mathrm{X}=\mathrm{CH}$<smiles>[R]n1cc(C(=O)O)c(=O)c2cc(F)c(N3CCN(CC(=[N+]=[N-])c4ccccc4)CC3)nc21</smiles><smiles></smiles>

35<smiles>C[C@H]1COc2c(N3CCN(C)CC3)c(F)cc3c(=O)c(C(=O)O)cn1c23</smiles>

33 levofloxacin organisms comparable or higher than the respective parent quinolones [40, 41]. To confirm the assumption that the conformational restriction of bioactive molecules offers the possibility of generating structures with increased potency Emami

$\mathrm{X}=\mathrm{CH}, \mathrm{N} ; \mathrm{R}=$ cyclo- $\mathrm{Pr}, \mathrm{Et}$

Figure 6. Structure of some piperazinyl quinolone antibacterials<smiles>CCN(C)C1COc2ccccc2C1=O</smiles><smiles>O=[NH+]C1c2ccccc2OCC1N1CCN(O)CC1</smiles>

35a-d<smiles>CCn1cc(C(=O)O)c(=O)c2cc(F)c(C(=O)O)cc21</smiles>

Scheme 14. The synthesis of N-(2,3-dihydro-4-hydroxyimino-4H-1-benzopyran-3-yl)-piperazinyl quinolones 
have been introduced restrictions in the mobility of the 2-hydroxyimino-2-phenylethyl moieties of 34. Convenient strategy for the synthesis of N-(2,3-dihydro-4- hydroxyimino-4H-1benzopyran-3-yl)piperazinylquinolones 35a-d as conformationally constrained analogs of $\mathrm{N}$ (phenethyl)piperazinyl quinolones $\mathbf{3 4}$ was elaborated [42] (Scheme 14). The synthesis of target piperazinyl quinolones $\mathbf{3 5}$ was first attempted by reaction of the corresponding 3bromo-2,3-dihydro-4H-1-benzopyran-4-one $\mathbf{1 5}$ with piperazinyl quinolone $\mathbf{3 0}$ and subsequent oximation. In the first step, different solvents, including DMF or MeCN were used in the presence of $\mathrm{NaHCO}_{3}$, which resulted in poor yields with unknown degraded products. The alternative strategy was the introduction of an oxime functional group onto the benzopyran ring in the first step, and then, a coupling reaction with piperazinyl quinolone. Along this route, stirring a mixture of compound 15 and three equivalents of hydroxylamine hydrochloride in methanol/water at room temperature gave 3-bromo-2,3-dihydro-4H-1benzopyran-4-one oxime. Reaction of the latter with piperazinyl quinolones (norfloxacin 30, enoxacin 31, ciprofloxacin 32, or N-desmethyl levofloxacin 33) in the presence of $\mathrm{NaHCO}_{3}$ in DMF at room temperature afforded N-(2,3dihydro-4-hydroxyimino-4H-1-benzopyran-3yl)-piperazinyl quinolones 35a-d in good yields. The stereochemistry of the oxime moiety of compounds 35a-d was assigned to be of $E$ orientation.

\subsubsection{Antibacterial activity of $\mathrm{N}$-(2,3-dihydro-}

\section{4-hydroxyimino-4H-1-benzopyran-3-yl)-} piperazinyl quinolones

A synthesized series of novel quinolone agents bearing a particular bulky and conformationally constrained bicyclic substituent (2,3-dihydro-4hydroxyimino-4H-1-benzopyran-3-yl- moiety) on the piperazine ring of 7-piperazinyl quinolones were evaluated against a panel of Gram-positive and Gram-negative bacteria. It was identified that incorporation of a $\mathrm{N}-(2,3-$ dihydro-4-hydroxyimino-4H-1-benzopyran-3yl)-scaffold on the piperazine ring allows manipulation of selectivity and potency of 7piperazinyl quinolones. All target compounds showed significant antibacterial activity against Gram-positive microorganisms and possess MIC values in the range of $0.024-0.78 \mu \mathrm{g} / \mathrm{mL}$ Among all target derivatives, the ciprofloxacin counterpart 35c, showed a high inhibition of all the tested Gram-positive bacteria, superior to the reference drugs, and displayed antibacterial activity at non-cytotoxic concentrations. Generally, compounds 35a-d were less active than the reference drugs against Gram-negative bacteria.

\subsection{3-Azinylchroman-4-ones conversion} products in reactions with nucleophiles

2.3.1. C-4 modified 3-pyridinylchroman-4nes 
Polfarmex S.A. recently patented [13] novel substituted N,N-dimethylaminoalkyl ethers of isoflavanone oxime as H1-receptor antagonists (Figure 7).<smiles>[R]c1cc2c(cc1[R])/C(=N\OCCCC)C([R])CO2</smiles>

$\mathrm{R}^{1}, \mathrm{R}^{2}$ independently $=\mathrm{H}$, Hal, $\mathrm{C}_{1 \_3}$ alkyl or $\mathrm{C}_{1-3}$ alkoxy; $R^{3}=$ Ph optionally substituted by $R^{4}, R^{5}=H$, $\mathrm{Hal}, \mathrm{C}_{1-3}$ alkyl, $\mathrm{C}_{1-3}$-alkoxy, $\mathrm{CF}_{3}, \mathrm{CN}, \mathrm{N}, \mathrm{N}-\mathrm{diC}_{1-3}$ alkylamide, carbo $\mathrm{C}_{1-3}$ alkoxy, $\mathrm{C}_{1-3}$ alkylsulphone groups; $\mathrm{R}_{3}=2-$, 3- or 4-pyridyl , $\mathrm{n}=1$ or 2 .

Figure 7 Substituted N,N-dimethylaminoalkyl ethers of isoflavanone oxime as $\mathrm{H}_{1}$-receptor antagonists.

The pharmaceutical composition containing them may be used in treatment of various diseases, such as asthma, hay fever, allergic rhinitis, atopic dermatitis, conjunctivitis, pruritis, and eczema, or other responses where histamine is released and acts on $\mathrm{H}_{1}$ receptors. The compound of formyla $\mathbf{3 6}$, in which $\mathrm{R}^{3}$ is pyridyl group containing nitrogen at different positions in the benzene ring can be obtained by reaction of 3-pyridylchroman-4-ones 37a-c with 2-(dimethylamino)ethoxyamine dihydrochloride in mixture of pyridine and dry ethanol, as shown in the example of 3-(pyridin-2-yl)chromane-4one 37a in Scheme 15. Patent specification is incorporated a three-step synthesis for 3- (pyridin-3-yl)- and 3-(pyridin-4-yl)chromane-4ones 37b,c, including palladium-catalyzed $\left(\mathrm{Pd}\left(\mathrm{PPh}_{3}\right)_{4}\right)$ cross-coupling reaction of 3halogenochromone with the appropriate pyridinylboronic acids to isoflavone derivatives [43], reduction with $\mathrm{NaBH}_{4}$ in alcohol to isoflavan-4-ol derivatives and oxidation of the hydroxyl group with pyridinium chlorochromate (PCC) to desired compounds [44]. Pyridinyl derivatives $37 \mathbf{b}, \mathbf{c}$ can be directly obtained by hydrogenation of isoflavone derivatives with a catalytic amount of palladium on etone [45]

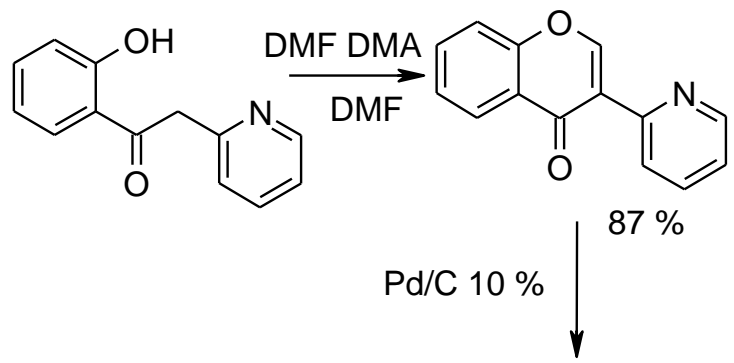<smiles></smiles>

Scheme 15 Synthesis of N,N-dimethyl-2-[[3-(2pyridinyl)-2,3-dihydrochromen-4-ylidene]amino]oxyethanamine

Another embodiment of the synthesis of the compounds $\mathbf{3 7 b}, \mathbf{c}$ given in the patent [11] is shown in Scheme 4 .

Note an approach to the synthesis of 3-(pyridin3-yl)chroman-4-one derivatives $37 \mathbf{b}$ through a 
new one-step gold(I)-catalyzed annulation reaction $[46,47]$ (Scheme 16).

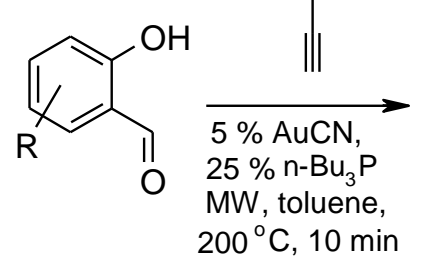

$\mathrm{R}=\mathrm{H}, 6-\mathrm{MeO}, 6-\mathrm{F}, 8-\mathrm{F}$<smiles>[R]c1ccc2c(c1)C(=O)C(c1cccnc1)CO2</smiles>

$(23-28 \%)$
Scheme 16 Synthesis of 3-(pyridin-3-yl)chroman-4-one derivatives

The attempts to synthesize 3-(pyridin-2yl)chroman-4-one and 3-(1-methyl-1Himidazol-5-yl)chroman-4-one using this approach were not successful, probably due to the reduced activities of gold(I) catalysts upon their coordination to the N-heteroaromatic alkynes. Should pay attention to the fact that when testing compounds $\mathbf{3 7 b}$ for anti- proliferative effects on human breast cancer cell line MCF-7, compounds 6-methoxy-3-(pyridin3-yl)chroman-4-one and 6-fluoro-3-(pyridin-3yl)chroman-4-one were identified as the most potent aromatase inhibitors with IC50 values of $2.5 \mathrm{lM}$ and $0.8 \mathrm{lM}$. and have a great potential for the development of pharmaceutical agents against breast cancer.

\subsubsection{C-4 modified and C-2 transformed 3-} (2-quinolyl)chroman-4-ones

Khilya et.al. have studied the behaviour of 7 methoxy-6-ethyl-3-(2-quinolyl)chroman-4-one (38) in the reactions with nucleophilic reagents such as hydroxylamine, hydrazine hydrate and quanidine.
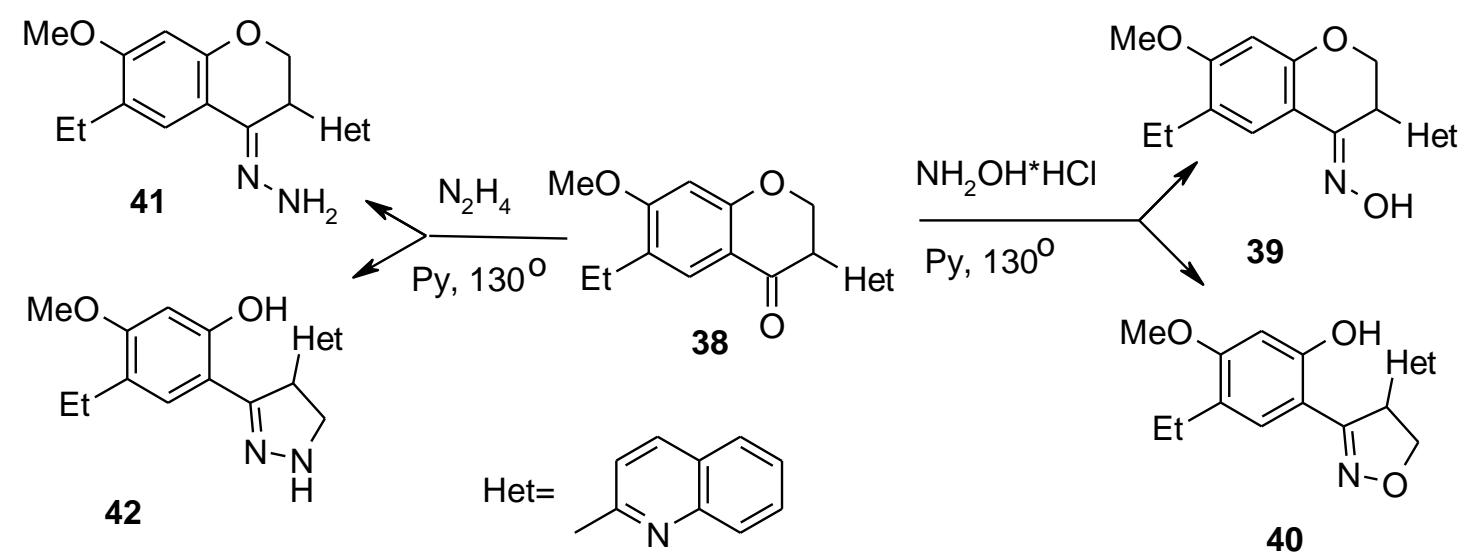

Scheme 17 Reaction products of 7-hydroxy-6-ethyl-3-(2-quinolyl)chroman-4-one with nucleophilic reagents

It should be noted that an attempt to carry out analogous reaction described for 3-azolylthe oximation reaction of this compound in chroman-4-ones [25, 26]. For 7-methoxy-6alcohol was not succesfull, in contrast to the ethyl-3-(2-quinolyl)chroman-4-one (38) the 
reaction took place in pyridine at $130^{\circ} \mathrm{C}$ and the reaction product was isolated in $75 \%$ yield. Taking into account the reactivity of chromanone derivatives toward $\mathrm{N}$-nucleophiles to two sites: carbonyl group and C-2 position and the results of studies on 3-azolylchroman-4ones, it was expected the formation of 3-(2quinolyl)chroman-4-one oxime (39), but did not exclude the formation of recyclization product the corresponding isoxazoline 40. To select from the alternative structures and to prove the structure of the isolated product was used NMR spectroscopy. In the proton spectrum of the alternative products should be completely identical spin system. That is why ${ }^{1} \mathrm{H}$ NMR spectrum can not serve to establish the structure of the synthesized compound. To prove the reaction product structure two-dimensional spectra and spectra of heteronuclear ${ }^{1} \mathrm{H}^{13} \mathrm{C}$ correlation were measured. On the basis of NMR experiments the synthesized compound has the structure of (Z)-7-methoxy-6-ethyl-3-(2quinolyl)chroman-4-one oxime (39), but one should note the presence of corresponding isoxazoline $\mathbf{4 0}$ in the synthesized compound spectrum HMBC as an impurity (5-7 \%).

The reaction of 7-methoxy-6-ethyl-3-(2quinolyl)chroman-4-one (38) with hydrazine hydrate in ethanol had not a success, whilst in pyridine the reaction was complete and the reaction product was isolated in $70 \%$ yield. To determine which of the positions of the chroman ring was attacked by hydrazine hydrate and accordingly what of the alternative products $\mathbf{4 0}$ or 41 was obtained two-dimensional spectra COSY, NOSY and spectra of heteronuclear ${ }^{1} \mathrm{H}^{13} \mathrm{C}$ correlation were measured. Combined application of homonuclear and heteronuclear correlation spectroscopy allows to reliably determine the structure of the synthesized compound as pyrazoline derivative 42. The reaction of 7-methoxy-6-ethyl-3-(2quinolyl)chroman-4-one (38) with guanidine in dimethylformamide was failed both in the presence and absence of potassium carbonate with heating.

\section{3-Azolyl-3-hydroxymethylchroman-4-one derivatives}

An electrophilic attack of formaldehyde on chromanones 43 resulted in small amounts of 3(1H-imidazol-1-yl)-3-hydroxymethylchroman4-ones (44) [5].

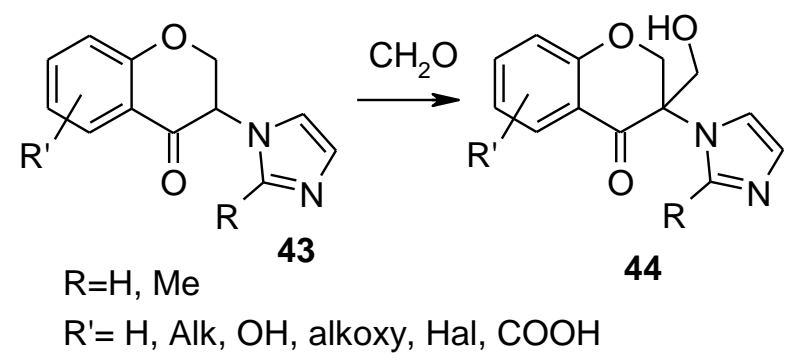

Scheme 18. The synthesis of 3-(1H-imidazol-1-yl)-3hydroxymethylchroman-4-one

\section{Reconversion into 3-azahetarychromonesl \\ 3-(1H-Imidazol-1-yl)chroman-4-one (13a) was reconverted to 3-(1H-imidazol-1-yl)chromone (45) by bromination with bromine in acetic acid and subsequent dehydrobromination in pyridine in $68 \%$ yield [48].}


<smiles>O=C1c2ccccc2OCC1n1ccnc1</smiles>

$13 a$
1. $\mathrm{Br}_{2}, \mathrm{AcOH}$ 2. Py, $\triangle$<smiles>O=c1c(-n2ccnc2)coc2ccccc12</smiles>

45
Scheme 19. The synthesis of 3-(imidazol-1-yl )chromone-

Partial reconversion process 7-methoxy-6-ethyl3-(2-quinolyl)chroman-4-one (38) in 7methoxy-6-ethyl-3-(2-quinolyl)chromone was observed by Khilya et al. when trying acylation enol hydroxyl compound $\mathbf{3 8}$ with acetic anhydride in pyridine at room temperature. The acylation reaction not passed, starting chromanone 38 and about $20 \%$ of the 7methoxy-6-ethyl-3-(2- quinolyl)chromone were isolated from the reaction mixture.

\section{Conclusions}

In conclusion, the synthesis of 3-azahetarylchroman-4-one derivatives and their chemistry are of great interest in the field of organic and medicinal chemistry. The chroman-4-one scaffold is an important intermediate and interesting building block in organic synthesis and design of new lead compounds in drug design and discovery.

\section{References}

[1] V. Semeniuchenko, U. Groth V. Khilya, Current Organic Synthesis, 2010, 7, 279.

[2] S. Emami, Z. Ghanbarimasir, Eur. J. Med. Chem., 2015, 93, 539.

[3] N.V. Gorbulenko, T.V. Shokol, V.P Khilya, Fr. -Ukr. J. Chem.., 2015, 3, 1, 4
[4] P. W. Feit, Acta Chem. Scand.. 1964, 18, 10,2401

[5] P. Cozzi, N. Mongelli, A. Pillan, J. Heterocyclic Chem. 1984, 21, 311.

[6] P. Cozzi, U. Branzoli, P.P. Lovizolo, G. Orsini, G. Carganico, A. Pillan, A. Chiari, J. Med. Chem., 1986, 29, 3, 404.

[7] P. Cozzi, N. Mongelli, A. Pillan, M. Bergamachi, P.P. Lovizolo, (Farmitalia Carle Erba S.p.A.), US 4.342.775, 1982.

[8] Farmitalia Carle Erba S.p.A., P. Cozzi, G. Carganico, A. Pillan, U. Branzoli, DE 3324069 A1, 1984.

[9] Farmitalia Carlo Erba S.R.L., (for USonly), P. Cozzi, G. Carganico,D. Severino, P.P. Lovizolo, A. Chiari, WO 8908646, 1989.

[10] D. Faucelli, A. Chian, P. Cozzi, P. P. Lovizolo, D. Severino, E. Ghiselli, J. Enzyme Inhib., 1994, 8, 3, 159.

[11] Chugai Seiyaku Kabashihi Kaisha, US 6645951 B1, 2003.

[12] Novogen Research PTY LTD (G. E.

Relly, A. Heaton, J. Faragalla, J. Bremner), WO 2004/039793 A1, 2004.

[13] Polfarmex S. A. (P. Kopczachi , M. Wosko, J. Walczak, K. Walczynski ), WO 2015/047113 A1., 2015.

[14] J. C. Lauter., S. Zhihua ., J. Fiordeliso, US 2006/40917 A1, 2006.

[15] E. J. Byrnes, K. H. Bartlett, J. R. Perfect, J. Heitman, Microbes and Infection., 2011, 13, 895.

[16] H. Ji, W. Zhang, Y. Zhou, M. Zhang, J. Zhu, Y. Song, J. Lú, J.Zhu, J. Med. Chem., 2000, 43, 2493.

[17] A. Rossello, S. Bertini, S. Lapucci, M. Marcia, A. Martinelli, S. Rapposelli, E. Herreos, B. Macchia, J. Med. Chem., 2002, 45, 4903.

[18] R. Rossi, A. Carpita, P. Pazzi, J. Mannina, D. Valensin, Tetrahedron., 1999, 55, 11343. 
[19] M. Tuncbilek, O. Bozdag, G. Ayhan-

Kilcigil, N. Altanlar, E. Buyukbingol, R. Ertan, Arzneim.Forsch., 1999, 49, 853.

[20] D. F. Rane, A. G. Fishman, R. E. Pike, Synthesis., 1984, 8, 694.

[21] R. Grigy, A. Liu, D. Shaw, S. Sugantan, D.E. Woodall, G. Yoganathan, Tetrahedron Lett., 2000, 41,7125 .

[22] S. Emami, A. Shafiee, Heterocycles 2001, 55, 11, 2059.

[23] S. Emami, M. Falahati, A. Banifatemi, M. Amanlou, A. Shafiee, Bioorg. Med. Chem., 2004, 12, 3971.

[24] S. Emami, M. Falahati, A. Banifatemi,

K. Moshiri, A. Shafiee, Arch. Pharm. Pharm. Med. Chem., 2002, 7, 318.

[25] S. Emami, M. Falahati, A. Banifatemi, A. Shafiee, Bioorg. Med. Chem., 2004, 12, 5881.

[26] S. Emami, A. Shafiee, Tetrahedron, 2005, 61, 2649.

[27] H. Ji, W. Zhang, M. Zhang, et al., J. Med. Chem., 2003, 46, 474.

[28] S. Emami, T. Banipoulad, H. Irannejad, A. Foroumadi, M. Falahati, M. Ashrafi-Khozani, S. Sharifynia, J. Enzyme Inhib. Med. Chem., 2014, 29, 2, 263.

[29] Schering Agrochemicals Limited, J.H. Parsons. S.E. Leach, A. N. Percival, A.D. Buss, D.E. Green, M. Uellor, EP 0247760 A2, 1987. Bulletin 87/49.

[30] S. Emami, S. Shojapour, M. A. Faramarzi, N. Samadi, H. Irannejad, Eur. J. Med. Chem., 2013, 66, 480 .

[31] S. Emami, A. Foroumadi, Arch. Pharm. Chem. Life Sci., 2009, 342, 541.

[32] S. Emami, M. Behdad, A. Foroumadi, M. Falahati, E. Lotfali, S. Sharifynia, Chem. Biol. Drug Des., 2009, 73, 388.

[ 33] M. Babazadeh-Qazijahani, H. Badali, H. Irannejad, M. H. Afsarian, S Emami, Eur. J. Med. Chem., 2014, 76, 264.
[34] S. Emami, A. Kebriaeezadeh, M. J. Zamani, A. Shafiee, Bioorg. Med. Chem. Lett., 2006, 16, $7,1803$.

[35] A. Kebriaeezadeh, S. Emami, M. Ebrahimi, M. Sharifzadeh, R. Khorasani, A. Shafiee, Biomed. Pharmacother., 2008, 62, 208.

[36] S. Emami, A. Kebriaeezadeh, N. Ahangar, R. Khorasani, Bioorg. Med. Chem. Lett., 2011, 21,655 .

[ 37] A. Ayati, M. Falahati, H. Irannejad,

S. Emami, DARU J. Pharm. Sci., 2012, 20, 46.

[38] F. Kállay, G, Janzsó, I. Koczor,

Tetrahedron, 1967, 23, 4317.

[39] A. Léavai, J Heterocyclic Chem.,

2002, 39, 1.

[40] A. Foroumadi, S. Ghodsi, S. Emami, S. Najjari, et al., Bioor. Med. Chem. Lett. , 2006, 16, 3499.

[41] A. Foroumadi, S. Emami, S. Mansouri, A. Javidnia, N. Saeid-Adeli, F. H. Shirazi, A. Shafiee, Eur. J. Med. Chem., 2007, 42, 985.

[42] S. Emami, .A. Foroumadi, N. Samadi, M. A. Faramarzi, S. Rajabalian, Arch. Pharm.. Chem. Life Sci., 2009, 342, 405.

[43] F. Xie, H. Zhao, L. Zhao, L. Lou, Y. Hu, Bioorg. Med. Chem. Lett., 2009, 19, 1, 275.

[44] M. Hoshino et al., Bull. Chem. Soc. Japan, 1988, 61, 3008.

[45] G. Amari, E. Armani, M. Civeli, M. Delcanale, E. Galbiati (CHIESI FARMACEUTICI S.p.A), EP 1229036, 2002.

[46] K. Bonfield, E. Amato, T. Bankemper, H. Agard, J. Steller, J. M. Keeler, D.Roy, A. McCallum, S. Paula, L. Ma, Bioorg. Med. Chem., 2012, 20, 2603.

[47] E. Amato, T. Bankemper, R.Kidney, T.Do, A. Onate, F. S. Thowfeik, E. J. Merino, S. Paula, L. Ma, Bioorg. Med. Chem., 2014, 22, 126.

[48] P. Cozzi, A. Pillan, J. Heterocycl. Chem., 1986, 23, 1693. 